\title{
An Interview with Roy Ellen
}

\author{
Nejm Benessaiah
}

Author address: School of Anthropology and Conservation, University of Kent, Canterbury, Kent, UK CT2 7NZ nejben00@gmail.com

Received: September 12, 2013

Volume: 5:31-39

Published: March 20, 2014

(C) 2014 Society of Ethnobiology

Roy Ellen completed his $\mathrm{PhD}$ at the London School of Economics (LSE) in 1973. During the following decade his work was influential in shaping some of the key questions of ecological (later environmental) anthropology (Ellen 1982). His work at this time also marked the opening-up of the Moluccas as an area for modern ethnographic fieldwork. This early research led in the 1980s to the development of his interests in the regional and historical contexts in which issues relating to production and resource management had to be understood (Ellen 1979), culminating in 2003 with the publication of On the Edge of the Banda Zone (Ellen 2003). Ethnobiological work had throughout this period also been a central feature of his work, particularly the way folk classification and underlying cognitive architectures are influenced by social and ecological conditions (Ellen 1993). His contribution to the critical appraisal of the role and form of local environmental ('indigenous') knowledge and of 'nature' as a comparative concept are reflected in a number of edited and co-edited works (Ellen and Fukui 1996; Bicker et al. 2000; Ellen 2006). He was elected a Fellow of the British Academy in 2003 and served as President of the Royal Anthropological Institute between 2007 and 2011.

I decided to undertake this interview with Professor Ellen, simply because I thought such a distinguished career deserved to be marked as he was retiring. Roy was happy to make time for our interviews, in the form of loosely structured conversation which, like the Arabian Nights, Roy pointed out, could have gone on forever, but I decided to draw the line at three sessions. Perhaps it could, and will go on to form part of a more in-depth biography, as I continued to discover other aspects and adventures of Roy's interesting life in the course of other contexts, much as one does in the field. Much is known about what ethnobiologists and anthropologists say about another people's lives; less is known about their own, apart from rare reflections, diaries and memoires. I found Roy's reflections a source of comfort as I embarked on my own PhD fieldwork, reassuring me as I fumbled around, making my own unique but comparable mistakes among the insights I gleaned. The following is an edited version of the original interview. I hope it will be as enjoyable to the reader as it was to me working on it.

Nejm: Can you tell us a little about your upbringing, and the influences that brought you to where you are today? Did your home environment influence your choices?

Roy: No, I think my parents were very supportive as far as they could be but I was brought up in a lower middle-class family [with] no previous academic tradition. My interest in anthropology developed fairly early. When I was about 11, I insisted that the thing I wanted most for Christmas was a copy of a book called The Dawn of Creation (Mansfield 1952), which was about human origins. And low and behold, this was delivered to me on Christmas Day!

At that stage you wouldn't expect me to have a knowledge of environmental anthropology or ethnobiology, they were not thought of as separate subjects - we're talking about the early 1960s. But I was interested in what is now called 'holistic' anthropology. I had a very strong conviction that the different aspects of anthropology - the biological, the sociocultural, and prehistory - had something to say to each other. I was very keen on going to University College London (UCL), because what they did then, and what they still do, is what the Americans call the 'four-field' style of anthropology, which was what appealed to me. But they didn't let me in. LSE, however, accepted me. The irony here is that I took exactly the same undergraduate degree at LSE that I would have taken at UCL. At that time at the University of London you could take an inter-collegiate degree, which was the BSc, the nearest you got to a 'holistic' anthropology degree. So, although I was registered at the LSE and did most of my social anthropology there, a small group of us - no more than six - used to migrate through the various central 
London colleges. We went to UCL for our biological anthropology and to the School of Oriental and African Studies (SOAS) for our linguistics, and the Institute of Archaeology for prehistory. So we were on the move all the time and we got to hear and listen to a whole range of luminaries. If I had simply been at the LSE it would have been much more restricted. So I was very happy with my undergraduate programme. That degree was sadly discontinued a few years after I had completed, so you can no longer do this kind of inter-collegiate degree.

Nejm: What took you to the University of Leiden?

Roy: I had positive interests in terms of the thematic matters that I wanted to pursue, but also had a strong negative motivation. I took the view that if I was to do ethnographic fieldwork anywhere, it would not be in any part of the world that had at any time been part of the British Empire [laughs]. We'd been fed the classics of sub-Saharan ethnography, the principal diet at the LSE, and indeed at UCL, at that time (notwithstanding [Raymond] Firth [who had worked in Malaya and Oceania]). Everything seemed to get drawn through the matrix of sub-Saharan African ethnography. Subsequently, we know that British anthropology tried to export some of these models to other parts of the world and they didn't quite work so well; so all that detailed work on lineage organisation by [Edward] Evans-Pritchard and Meyer Fortes in Africa, when you tried to use it to model kinship in the New Guinea highlands, didn't work [laughs]. I knew that a diet of sub-Saharan ethnography had been very good for me, and I cut my theoretical teeth on it, but I thought that if I wanted to do fieldwork I needed to go somewhere else, so it was the Dutch empire really.

What interested me particularly was that area between island Southeast Asia and the Pacific where there seemed to be a zone of transition, which I subsequently learnt was called Wallacea. The interesting thing about Wallace's line is that it not only works for fauna and flora, but it also works with human cultures and populations. There is a break that falls somewhere in that area, which means that there are very different kinds of social and cultural features on either side of the line.

The person I worked most closely with at the University of Leiden was a man called Patrick De Josselin de Jong, the nephew of J.P.B. De Josselin de Jong, who is the more famous [of the two] because of his influence on Lévi-Strauss. Lévi-Strauss's work on structuralism as applied to kinship was strongly anticipated by a generation of Dutch anthropologists, of which J.P.B. De Josselin de Jong was one. It was something about the structure of the marriage systems found in parts of eastern Indonesia and Sumatra that gave rise to these Dutch structuralist analyses, and these in turn influenced Lévi-Strauss. I read that stuff and found it intriguing. Indeed, I ended-up working amongst an Indonesian people on the island of Seram (the Nuaulu) who have a classic symmetrical crosscousin marriage system of the kind that would have very much excited De Josselin de Jong or LéviStrauss. Part of the problem was that [the work of] the Dutch anthropologists wasn't based on very good (or firsthand) ethnography, mainly missionary accounts. Some of the missionary accounts were excellent, but other accounts were a bit dodgy. So, in a way it was the very weaknesses in the data that allowed the construction of these rather grand theories. If they'd had more data they couldn't have sustained the theories.

Nejm: What got you into shifting cultivation?

Roy: Well, I knew that I wanted to do something on ecology and environmental relations, being very much influenced by Roy Rappaport for example, and other people of that generation. I could have worked amongst hunters and gatherers. The literature at that time [for Indonesia] wasn't particularly good, and we didn't even know that some populations actually still existed. It was much later [in 1976] that I was to personally encounter groups of hunter-gatherers, in south-eastern Sulawesi. They'd existed there for years and few people had really known about them. Or, I could have worked on maritime issues in that part of the world and done something on fishing. But I suppose, in reading around my Southeast Asian ethnography on likely themes that I could pursue as a research student in eastern Indonesia, shifting cultivation was an obvious contender, because there had had been some very interesting monographic work published on the subject during the early 60s, and before. [Harold] Conklin's work, for example, on the Mindoro Hanunóo. So again it was a current issue. And of course the interesting thing about Conklin is that he had developed systematic, some might say obsessively meticulous, methods and checklists for analysing it, which tied in with his particular interest in looking at local environmental knowledge systems (Figure 1). 
And this is where, if you like, the 'ethnobiological knowledge' passion begins to kick in. That came in as a secondary consideration for me, through Rappaport, who had theorised cognized or home-made models, and through Conklin's interest in exact ethnographic description. Ethnographers such as Rappaport made shifting cultivation a 'sexy' theoretical subject, something that went beyond description of peoples' equipment and subsistence habits, but introduced exciting new concepts such as carrying capacity and negative feedback, and had a kind of dynamic component. After all, shifting cultivation was something that went in cycles, and these cycles had implications for forest ecology and human settlement patterns. A lot of my Ph.D. was about understanding the form that human settlement takes in areas where shifting cultivation is the main form of subsistence.

Nejm: Maybe now would be a good time to get into your fieldwork.
Roy: Everybody says that first fieldwork is formative, but I suppose if you're that young [I was just 22], it's even more formative [laughs]. Research training existed only in a rather informal way at the LSE in the late 1960s. In some sense I suppose I went into the field not quite knowing how I was going to develop my data! There can't have been any more than 10 [research training] sessions [at LSE] overall. And one of them involved telling us how important it was to buy the right kind of shotgun, and how you should buy a Land Rover that had a winch on the bonnet so that you could pull yourself out of a swamp [laughs]. And that constituted fieldwork training. It is true that they also taught you how to collect demographic data and how to use the international phonetic alphabet to transcribe unwritten languages, things like that, and a little bit on survey design, but it was all pretty basic.

Nejm: What was it like when you arrived?

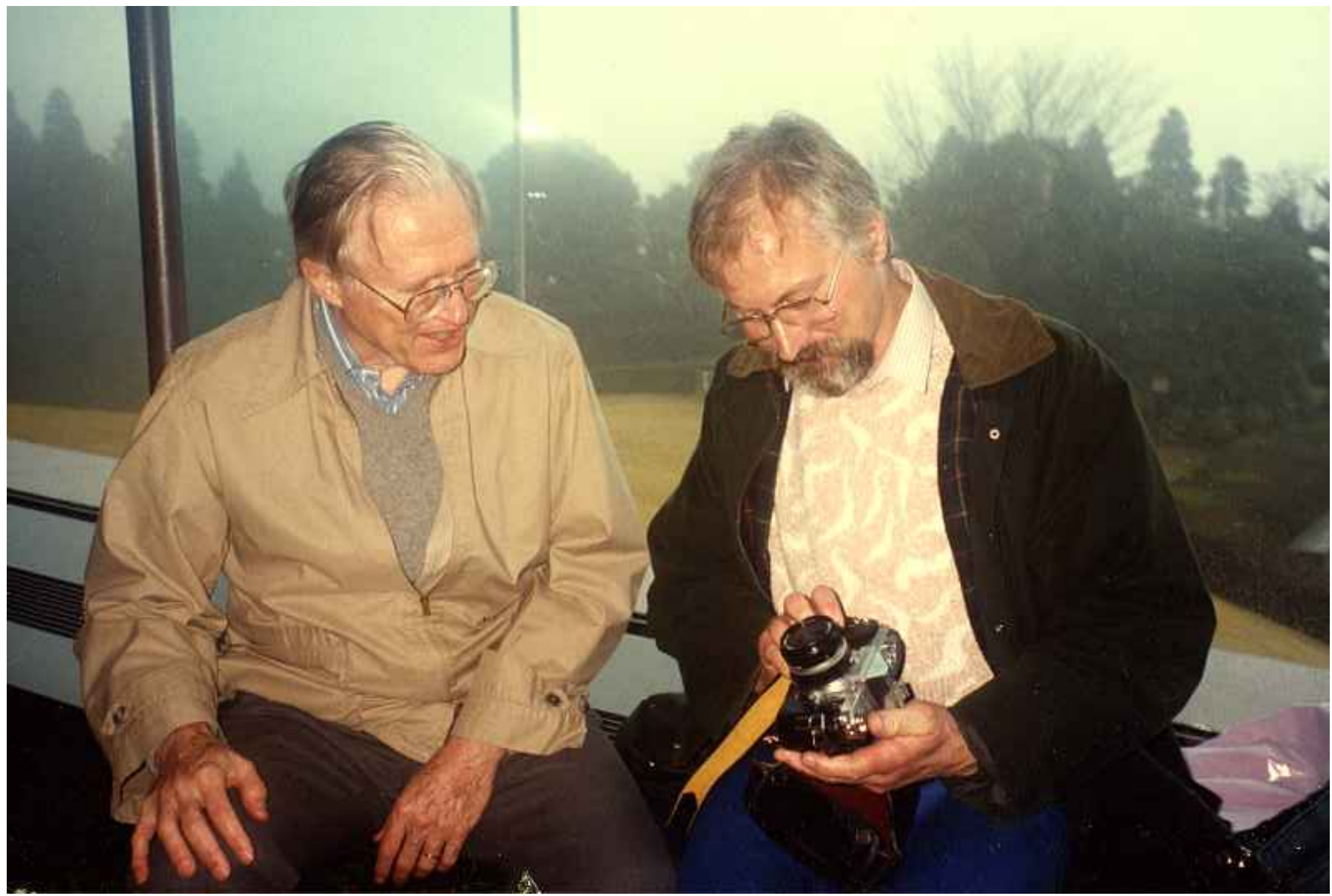

Figure 1. Roy Ellen with Harold Conklin, explaining the finer points of his trusty Nikkormat at the 'Redefining Nature' conference in Atami, Japan, 1992. Hal had been an intellectual hero of Roy's from his time as a postgraduate student at the LSE, and was over-awed to find himself sharing a Japanese communal bath on their first encounter. 
Roy: Although the Nuaulu [of central Seram] at that time were mostly living on the coast, their entire subsistence orientation was to the inland and upland areas. They moved to the coast in the late $19^{\text {th }}$ century as part of the Dutch pacification programme, but nevertheless, they were still extracting from the upland forests, and they'd retained a lot of the institutions and practices that interested me, whereas there had been much depopulation and acculturation in West Seram.

So I was very pleased to discover the Nuaulu after several introductions and recommendations. I hadn't read anything about them, not that there was much anyway. What was interesting about the Nuaulu was less that they were remote and isolated, but that they had a history of contact with the wider world through trade, and contact with the Dutch, going back some centuries. And once you get [to Seram] you can understand this, because a lot of their social structure is really dependent upon certain kinds of exchange with the outside world. Their valuables are Chinese porcelain and red cloth, and all kinds of things that could only be obtained through trade. And after all, this had been an area of global production of spices going back centuries, until the $16^{\text {th }}$ century without any direct European contact. So they'd had a lot of contact with the outside world, but they'd sort of retained their independence in many ways.

Nejm: How were your first few days among the Nuaulu? What practical situations were you encountering? How were you received? Any embarrassing situations?

Roy: Plenty of embarrassment, of course. Some of the embarrassment followed a few months later, as I realised the implications of having accepted the invitation to live in a particular house. I was offered a house [in Rouhua] that happened to be vacant (Figure 2). At the time I was collecting zoological specimens with kit given to me by the Natural History Museum in London. This was in support of my work on ethnozoology. I humanely killed the specimens and injected them with a little formalin, and thereafter preserved them in large polythene containers. After about six months in the field, I became a little concerned because when I returned to my house I would find a reticulate python curled up on my sleeping mat or hanging in the rafters. I mentioned this to Komisi, the head of clan who owned the house. He explained to me that this was obviously going to happen because the principal totem of his clan was the reticulate python. He explained that I would have to remove the polythene containers with the snakes, and would have to pay a fine. This was a classic lesson in participant observation, because I had to learn how to go through the ritual of paying a fine, a plate and five lengths of red cloth that had to be bought at the local Chinese kiosk about 3 or $4 \mathrm{~km}$ away.

Nejm: so the fine was for offending the snake spirit?

Roy: The fine was for offending the ancestral snake spirit. And everything was alright after that! The thing about doing fieldwork is that because you're going into an area where you don't know the people and you certainly don't know their cultural rules and values, the scope for embarrassment is enormous. And if you are working with a people who are being incredibly tolerant, because they're being tolerant you probably don't learn the rules as quickly as you ought to.

Moreover, Nuaulu are always looking for explanations of misfortune. No misfortune is considered random. [Have you] read Evans-Pritchard on Azande Witchcraft? It's the same kind of situation, where a concatenation of circumstances are the problem. They can understand fully to their own satisfaction that the reason the bamboo slats inside a house break at a crucial moment is because there are ants eating through them, but they might want to know why it's happened to them at that particular time! And it will usually be that something they have done previously has angered ancestral spirits. It's usually the ancestral spirits. So it could be that anything they may have done wrong in the past would be mobilised as a possible explanation. And it's one of their main preoccupations, trying to prevent these bad concatenations of circumstance and thinking of ways in which they unknowingly have offended the ancestors. It's a major preoccupation, and they constantly talk about the burden of monne, the burden of custom. They say things like "it's alright for you Christians and Muslims, you don't have the burden of custom. Every few minutes ancestors may be interfering in our lives, so we have to make sure they've been placated or make sure we've done things in the correct way". So, the important thing about ritual is that it must be done precisely in the correct way. Any deviation from the correct way may result in misfortune.

Nejm: Did you find any conflict with your own belief system or lack thereof? 


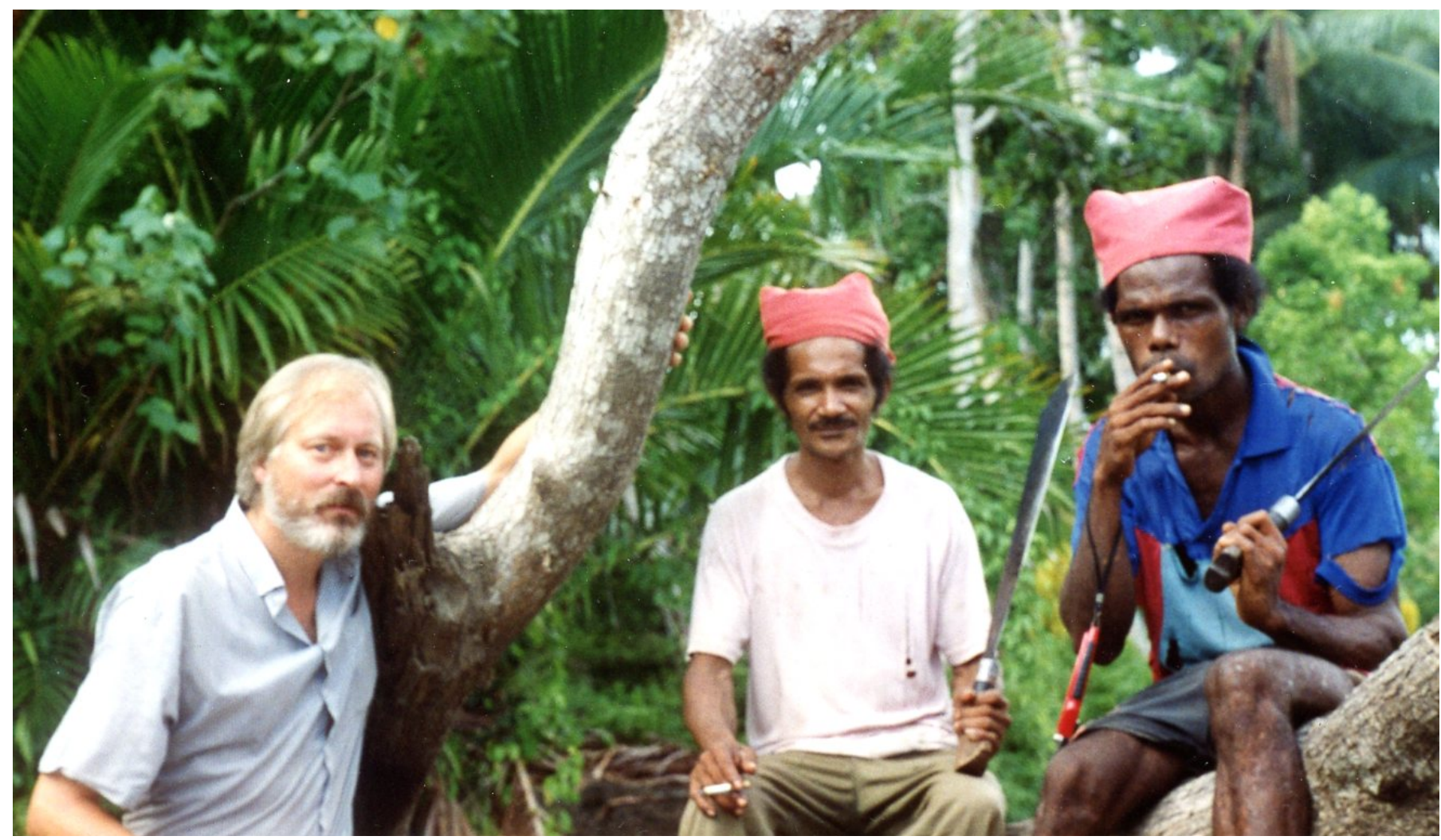

Figure 2. Roy Ellen with Anarima and Heunaka, near the Nuaulu village of Rouhua, south Seram, 1996.

Roy: Yes, I think there were moments. I had to have some kind of identity, and at least initially my identity was that I was a Christian. You know, I had to have that identity, I couldn't avoid [it]. Local people needed to place me within some field of understood religious identities, even though there was a certain amount of tension between Indonesian Christian and animist groups. But the longer I was there, the more I felt confident I could identify with the Nuaulu themselves, and my position as a cultural Christian seemed less important to them.

I think that whenever you're a fieldworker, you question some local beliefs and practices, but if things happen you have to enter into the spirit of it. Because the alternative would be impossible... it's easier for them to understand that you are a cultural Christian [or a cultural Muslim, Jew or Hindu] than for you to say you don't have any sort of affiliation at all; they would find that difficult to handle. And for Nuaulu certain kinds of belief, like the belief in spirits, are so self-evident that questioning them is extremely difficult. They just assume that if you're human you must share in these kinds of beliefs. For them it's absolutely clear, like they believe that everybody has hookworm and body lice - you're not human unless you have hookworm and body lice because everybody there has them. It's part of being human; they really do think that.

Nejm: Can you describe some impressions of the first few days?

Roy: I suppose you have to get used to a new environment, and Nuaulu villages are different to those of other people on Seram. At that time when I first arrived [early 1970] houses were entirely made of timber and sago leaf stalks and so on, and they were incredibly smoky, with a pall of smoke hanging over the village and the house in particular. It was also very humid, oppressively so. And although most Nuaulu villages are on or near the coast, they're highly connected with the forest in a way in which other non -Nuaulu villages aren't. So, if you go to your average coastal Muslim village, the village itself is probably surrounded by coconut groves for some distance until you get to the forest, whereas the Nuaulu, their gardens, their swiddens, tend to be several kilometres away in the middle of the forest, so the whole orientation is to the forest, the presence of the forest 
is everywhere.

Nejm: Is there any kind of dualistic division between the forest and the village, or are there more grey areas?

Roy: Absolutely. You can almost say that the Nuaulu case presents a defence for the more traditionalist view of how nature is constructed. They don't have a word for nature, at least they didn't have, but there is nevertheless a strong conceptual difference between the village and the forest; the forest is a kind of proxy for nature, because the rules governing behaviour in the forest are different from those governing behaviour in the village. So for example, thinking of linguistic rules, there are certain expletives you can use in the village that you can't use in the forest because they're considered as mocking animals. So as you pass from the village to the forest you often perform a ritual, make a small offering to the spirits of the forest, so there's a very clear boundary as you go into the forest. And Nuaulu talk about the village as being like an island. And that's a metaphor that crops up in all kinds of symbolic contexts. So yes, there's a strong sense of dualism as between the village and the forest, and hence between culture and nature.

Nejm: Did those sort of deeper realisations take a while to conceptualise?

Roy: Well, I don't know at what point that interpretation suddenly occurred to me. They [Nuaulu] certainly didn't draw a little map and show me how it all worked. Of course, one of the things about doing ethnographic research anywhere is that you do a literature survey that has told you about the peoples in this area. And so you do have certain expectations about how things are supposed to work. In the context of, especially, eastern Indonesia there is this longstanding Dutch structuralist tradition. And so I was expecting these sorts of elaborate conceptual patterns. And so when they came along I was quite pleased! (laughs). One thing it did teach me though, was that you have to be careful because it is terribly easy to make your data fall into some kind of neat system of binary oppositions. And a lot of my professional career, when I haven't been doing ethnobiology, has really been a critique of this Dutch position. Although you could say that the Nuaulu work with some kind of 'cognitive geometry' in which they use different kinds of oppositions to think about the world around them, there is no neat, overarching symbolic structure. It's a very dynamic kind of situation, and the problem with the Dutch structural- ists was that they were working with very inadequate ethnographic materials, and they thought there were these rather tight cosmological models where everything neatly slotted together. But that certainly hasn't been my experience. So if you take the concept of nature: on the one hand certainly, there is this strong contrast between the village and the forest, but then, equally there is a series of symbolic gradations, so the village periphery is more liminal than the village centre, less symbolically charged; and if you go into the forest there are clearly areas that are less 'part of nature' than others in the sense that they have been modified by humans: other village sites, sacred groves, all that kind of thing. So there wasn't an easy neat structuralist interpretation of what was going on.

Nejm: How about your methodology? I haven't managed to look at your thesis yet for that section.

Roy: Well, there's not a separate methodology section in there I'm ashamed to say. Those were the days, especially in anthropology, when you weren't expected to have a methodology section. The methodology was implicit. Though I suppose I was more methodologically conscious or literate than some other people, who simply imbued the ethos of participant observation, simply filling their notebooks with anything they found out as they went along. Because I had been reading Conklin on how to do research on shifting cultivators, and I had been reading some of the early work on the proper way to conduct ethnobiological research, I think I was more methodologically sensitive and explicit in those specific areas, and on the more technical things. Even at that stage I had honed-up on particular protocols for doing swidden surveys and transects. But none of that was really part of the anthropology that I'd learned at the LSE! That all had to be acquired because I was doing work on ecology and ethnobiology.

Within my thesis, above the more technical level, the kind of model I was using to try to integrate different kinds of data was in tune with something called 'generative analysis', which had been developed by Frederick Barth. In the way I used it, what it most resembled in retrospect was Vayda's analytic induction. My thesis was called 'Nuaulu settlement and ecology' - and its objective was to understand the wider Nuaulu pattern of settlement as an outcome of the various factors that impacted upon it. So clearly if they [the Nuaulu] are conducting shifting cultivation, then the requirements for the effective conduct of 
shifting cultivation were part of that: you had to have a certain amount of land in fallow, it had to be rotated, and this kind of stuff. And at the same time there were clearly non-ecological factors, almost symbolic factors. We've already talked about the symbolic structure of the village, and that's a very good example. You know, the literal pattern of the Nuaulu village, although you can't always see this when you walk into a village, is dictated in part by these symbolic considerations. So, at the centre, ideally, in every Nuaulu village is a big ritual house. And then on the periphery are the menstruation huts for the women. Now that's entirely in accordance

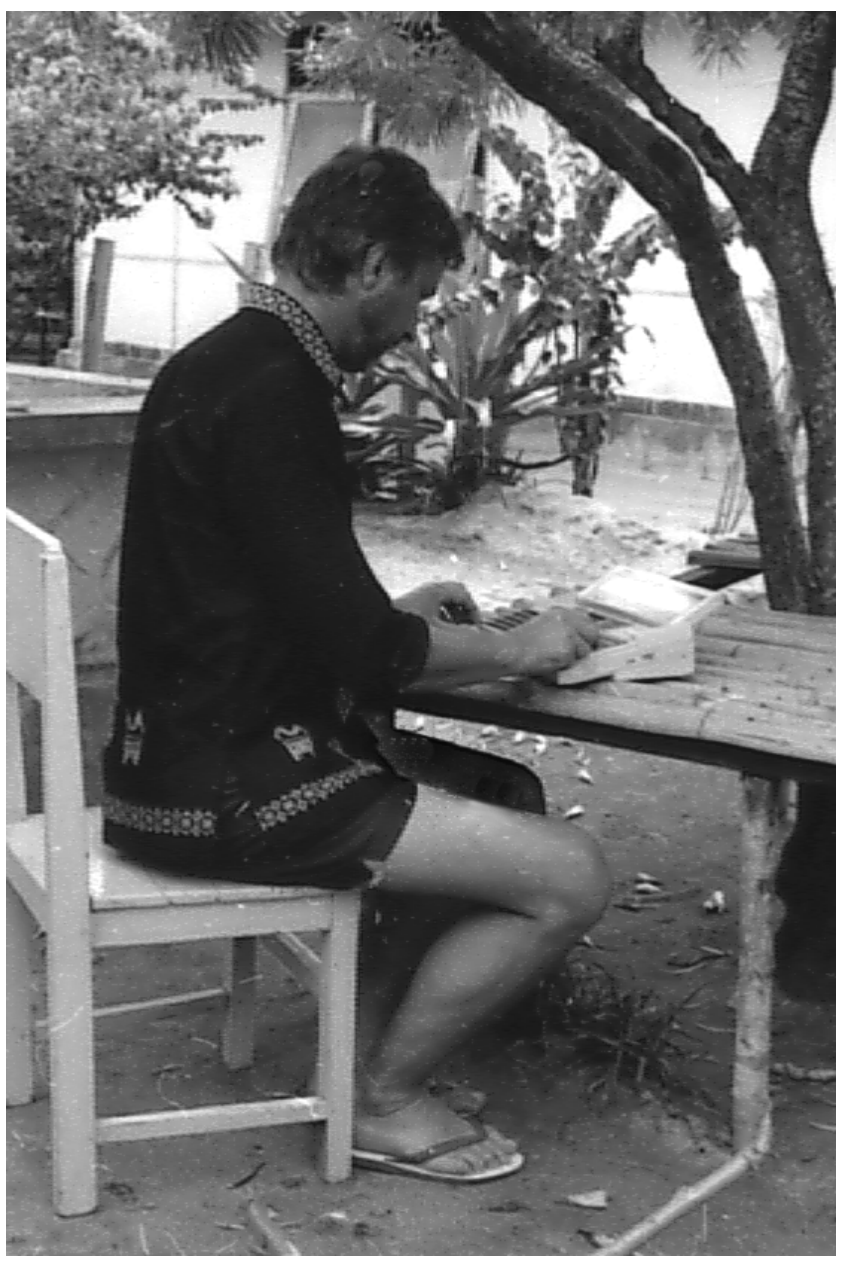

Figure 3. Roy Ellen on the coral atoll of Geser in southeast Seram, April 1986, while undertaking work that led to the publication of On the Edge of the Banda Zone. The photograph might be of some interest to historians of field computing, as it depicts Ellen with a 'portable' gifted by Epson, run on solar batteries and saving to minicassettes. with the symbolic expectations. But when you walk into the village you can't see it as a set of concentric circles of course; but it's there. Such symbolic considerations are quite important when you are explaining the juxtaposition of different components of the settlement pattern. Why do particular clans live in particular areas? So the clan Matoke is a primus inter pares - it provides the 'lord of the land', who has certain responsibilities for supervising the matter of land relations, over all other clans. And all their [Matoke] houses have to be located in what we would call the northeast corner of the village. You can't immediately see this, it has to be inferred. I mean, the point of the generative analysis was that somehow the visible pattern you could see, was generated by the interaction of these different kind of factors. And that's what I was wrestling with. How you would resolve the more mundane economic and ecological factors with the more religious and symbolic things. That's something else that was connected with my methodological ruminations at the time.

Nejm: Was it an easy place to live in?

Roy: You mean in terms of things physical?

Nejm: Well yes, but also in terms of friendliness?

Roy: Oh yes, it was. And again, another one of those important truisms about fieldwork is the importance of children. Children were very interested in any outsiders. They may be a little scared to begin with but that quickly disappears when they interact with you. And of course they're much more tolerant than adults and so learning the rudiments of language, and indeed other cultural rules, is so much easier. It's a good way to do it; I would recommend it. Physically, it [life] was different, but I think I was expecting that; in fact, in certain respects I found it more tolerable than I might have had reason to expect. The little hut that they'd given me was no bigger than this room [Roy's office], divided into two. Did I tell you about Evans-Pritchard's dictum, 'take two tables?'

\section{Nejm: Yes!}

Roy: Well they'd actually provided me with two tables (Figure 3)! And there's this big slab of wood - that was one, and it was the right height, and I could use my typewriter, and have my Tilley lamp hanging up and so on. And then I had one [a table] where I had all my food preparation going on. And it became quite a social centre. During the day I might be out and about, measuring a swidden or attending a ritual 
as one does. And then in the evening I'd come back and start writing up my notes, light the Tilley lamp, and have something to eat. And of course the Tilley lamp was the brightest lamp in the village and so it attracted everybody. So that was quite productive as well; because people come to you it became a sort of social meeting place. And so I learnt a lot during those evening sessions round my table. People were always very generous with food. I had an arrangement whereby I would buy sacks of rice and sugar and those sorts of things you would get from the stores, salt and so on, and there'd be a rough and ready exchange. People would give me some cassava roots or a bit of meat or something, and I would give them some rice. So that worked very well. I was never short of food or anything. And of course I dispensed minor medical assistance as well. So that was the exchange relationship that made collecting fieldwork data work, really. And I think at that stage people were perfectly happy with that arrangement. On subsequent visits, as I ceased to be a student and became a 'big man', they expected more of me, and as indeed the whole area became a great deal more commoditised. From the 1980s the government put through a road, and there were incoming transmigrants, so there was much more contact with the outside world. Nuaulu women would go off to the market and sell tubers and stuff. So as it was much more of a cash economy, so their cash expectations of me were probably correspondingly higher (laughs).

Nejm: So the last question would be... I've been going over some of your recent works, and not so recent, such as the 2006 Ethnobiology of Humankind and other syntheses, and I'd love to hear where you see ethnobiology going, whether in a more quantitative direction, or a more qualitative and social science direction while very much grounded in biology and ecology?

Roy: I would like to think there's room for both. There's certainly a lot of interest in ethnobiology. And I think, intellectually, it's not going to disappear, and I think it's certainly going to be driven by some of the applied issues. For example, conservation scientists see that it can augment what they're trying to do, and there's the whole indigenous rights issues there, so I think it's inevitably going to be much more applied. What I was explicitly trying to do in that special issue in the Journal of the Royal Anthropological Institute was to bring it back into anthropology where I thought it belonged, because I think ethnobiology as a set of practices, and also the sorts of intellectual issues it raises, can contribute in major ways to those questions we consider to be central to the anthropological project.

Nejm: Anything else in terms of themes? We were talking about drawing things together within anthropology through a co-evolutionary framework. The International Society of Ethnobiology is doing some important work.

Roy: What I like about the International Society of Ethnobiology is that there's always a tension, and it's an important tension, a positive tension between the science and the activism. It's an organisation whereby scientists and researchers can actually get together and share concerns with indigenous activists and people who own and wish to protect knowledge, as well as use it and understand it. Ideally you might think these aspects mutually supportive, and to a considerable extent they are, but there are tensions because, inevitably, the project of wanting to protect indigenous knowledge is a highly political one, and it doesn't always sit comfortably within the scientific context and the ways of trying to understand the world that anthropologists, and perhaps even academic ethnobiologists would prefer. But you need that kind of tension, and I think intellectually the world would be a far less satisfying place to live in if [these kinds of tensions] didn't exist.

\section{References Cited}

Bicker, A., R. F. Ellen, and P. Parkes, eds. 2000. Indigenous Environmental Knowledge and its Transformations: Critical Anthropological Perspectives. Harwood Academic, Amsterdam.

Ellen, R. F. 1979. Sago Subsistence and the Trade in Spices: A Provisional Model of Ecological Succession and Imbalance in Moluccan History. In Social and Ecological Systems, edited by R. F. Ellen and P. Burnham, pp. 43-74. Academic Press, London.

Ellen, R. F. 1982. Environment, Subsistence and System: The Ecology of Small-Scale Social Formations. Cambridge University Press, Cambridge.

Ellen, R. F. 1993. The Cultural Relations of Classification: An Analysis of Nuaulu Animal Categories from Central Seram. Cambridge University Press, Cambridge. 
Ellen, R. F. 2003. On the Edge of the Banda Zone: Past and

Present in the Social Organization of a Moluccan Trading

Network. University of Hawaii Press, Honolulu.

Ellen, R. F., ed. 2006. Ethnobiology and the Science of

Humankind. Wiley-Blackwell, Oxford.

Ellen, R. F., and K. Fukui, eds. 1996. Redefining Nature:

Ecology, Culture, and Domestication. Berg, Oxford.

Mansfield, J. C. 1952. Dawn of Creation. George G.

Harrap, London.

\section{Biosketch}

Roy Ellen is a retired Emeritus professor of Anthropology and Human Ecology with a particular interest in Ethnobiology, still based at the University of Kent. His research is currently focused on the applications of cognitive anthropology to the history of science, the reproduction of Nuaulu ritual cycles, and understanding the management and significance of cultivar diversity amongst home gardeners and farmers in the British Isles and in the Moluccas.

Nejm Benessaiah is a PhD candidate in Ethnobiology at the University of Kent. His research concerns how farming communities deal with and affect change in arid ecosystems of North Africa within the shifting negotiation of knowledge, power, and values in relation to the state and market economy. 